\title{
A retrospective comparative study of mortality and causes of death among patients with metal-on-metal and metal-on-polyethylene total hip prostheses in primary osteoarthritis after a long-term follow-up
}

\author{
Tuomo Visuri*1, Håkan Borg², Pekka Pulkkinen ${ }^{3}$, Pekka Paavolainen ${ }^{4}$ and Eero Pukkala ${ }^{5}$
}

\begin{abstract}
Background: All patients with total hip arthroplasty (THA), especially those with metal-on-metal (MM) THA, are exposed to metallic particles and ions, which may cause total or site-specific mortality. We analyzed the causes of total and site-specific mortality among a cohort of patients with MM and with metal-on-polyethylene (MP) THA after a long follow-up time.

Methods: Standardized mortality ratios (SMR) of total and site-specific causes of death were calculated for 579 patients with MM (McKee-Farrar) and 1585 patients with MP (Brunswik, Lubinus) THA for primary osteoarthritis.

Results: Mean follow-up time was 17.9 years for patients with MM and 16.7 years for patients with MP. Overall SMR was 0.95 for the MM cohort and 0.90 for the MP cohort, as compared to the normal population. Both cohorts showed significantly decreased mortality for the first decade postoperatively, equal mortality over the next 10 years, and significantly increased mortality after 20 years. Patients with MM THA had higher cancer mortality (SMR 1.01) than those with MP THA (SMR 0.66) during the first 20 years postoperatively, but not thereafter.

Conclusion: Both MM and MP prostheses are safe based on total and site-specific mortality of recipients during the first 20 postoperative years in comparison with the general population.
\end{abstract}

\section{Background}

Metal-on-metal (MM) total hip arthroplasty (THA) and especially MM hip resurfacing techniques have recently regained popularity due to successful mid-term results in young patients [1-4]. Patients with these prostheses will be exposed to cobalt and chromium particles and ions for decades.

MM articulations give rise to particles that are typically 20 to $90 \mathrm{~nm}$ in size, with a mean size of approximately 50 $\mathrm{nm}$ [5-7]. Because of their small size, MM particles disseminate widely throughout the body, particularly to the lymph nodes, liver, spleen, and bone marrow [8-12]. The number of these metallic particles is estimated to be 1000

*Correspondence: tuomo.visuri@helsinki.fi

1 Research Institute of Military Medicine, Helsinki, Finland Full list of author information is available at the end of the article times greater than that from metal-on-polyethylene (MP) prostheses [13]. These particles have a large surface area, and their degradation increases the concentrations of cobalt and chromium ions in the body fluids. An autopsy performed more than 25 years after successful implantation of a McKee-Farrar prosthesis (Howmedica International, Limerick, Ireland) showed elevated levels of cobalt and chromium in liver, even in the absence of specific particulate debris in remote sites. This finding suggests that the metal is stored in the liver as organometallic complexes or in nanoparticulate form so small that it is beyond the resolution of electron microscopic analysis [11].

In an early study [14], nine patients with a McKee-Farrar prosthesis had an approximately 3-fold elevation of chromium and an 11-fold elevation of cobalt in the whole 
blood, and a 15-fold elevation in chromium in the urine, compared with the preoperative values. High serum metal levels were observed in eight McKee-Farrar patients after a 20-yearfollow-up, 9-fold higher for chromium and 3-fold higher for cobalt compared with controls [15]. Five patients with Ring prostheses (Downs Bros, Mitcham, United Kingdom) for an average of 33 years had approximately 5 -fold greater serum cobalt levels and 3-fold greater serum chromium levels compared to patients with a primary or revised MP prostheses or patients with osteoarthritis (OA) and no implants [16]. Elevated serum chromium and cobalt levels have also been reported in patients with MP prostheses, but the concentrations are lower than those in patients with MM prostheses [17].

Both in vivo and in vitro studies demonstrate chromosomal aberrations and DNA damage in association with debris from cobalt chromium MM and MP prostheses. An increase in chromatid breaks and gaps are observed in the bone marrow adjacent to the worn implant [18]. Compared with patients at primary arthroplasty, patients with mixed types of cobalt chromium prostheses who underwent revision arthroplasty had a 2.5 -fold increase in the number of peripheral blood lymphocytes in aneuploidy and a 3.5-fold increase in chromosomal translocations [19]. Debris from worn hip and knee prostheses damages chromosomes in a dose-dependent manner in human tissue culture, and is specific to the type of metal. Cobalt and chromium concentrations correlate with chromosomal breakage and aneuploidy events, and titanium concentrations correlate with aneuploidy events [20]. A 2-year prospective study in patients with MM hip prostheses revealed a significant increase in whole blood cobalt and chromium concentrations as well as in chromosome aneuploidy and translocations in the peripheral blood lymphocytes [21].

Therefore, patients with MM and MP hip prostheses are exposed to cobalt and chromium particles and ions, which are potentially genotoxic. Long-term exposure to these metals may affect mortality in these patients. We analysed the causes of death in patients with MM and MP total hip articulations over a long follow-up period.

\section{Methods}

Basic patient material was identified from the medical records of two regional orthopaedic hospitals in Finland. When only patients diagnosed with OA were selected, the MM arthroplasty group comprised 579 patients who underwent a McKee-Farrar THA (all cobalt-chromiummolybdenum) between 1967 and 1973, and the MP series comprised 1585 patients who had either a Brunswik or Lubinus (Waldemar Link GmbH \& Co., Hamburg, Germany) prosthesis (cobalt-chromium-molybdenum stem) and who were operated on between 1973 and 1985. Data for this patient population were reported previously [22]. The proportion of women in the MM group was $66 \%$ and that in the MP group was $61 \%$.

The dates and causes of death during 1971-2005 for the cohort members were obtained from Statistics Finland by record linkage using a personal identifier code as the key. The coverage of the cause-of-death statistics is virtually complete.

Calculation of person-years at risk started from the operation and ended at death or closing-date of the study, December 31, 2005. The number of observed cases for each cause of death and person-years at follow-up was stratified by sex, calendar period, 5 -year age group, and follow-up time since the operation. The expected number of patients to die from each cause was calculated by applying the number of person-years in each stratum to the corresponding mortality rate in a similar Finnish population. The calendar periods used were 1971-1974, 1975-1982, 1983-1990, 1991-1998, and 1999-2005; and the follow-up categories were $<2,2-9,10-19$, and $>20$ years since the operation. The standardized mortality ratio (SMR) was expressed as the ratio of observed and expected number of cases. The $95 \%$ confidence intervals ( $95 \% \mathrm{CI}$ ) were defined based on the assumption that the number of observed cases followed a Poisson distribution. The relative mortality risk between patients with MM or MP THA was calculated as the rate ratio (RR) of the two SMRs. The 95\% confidence limits of the RR were calculated assuming Poisson distributions.

The list of causes of death included all 53 categories for which Statistics Finland routinely produces mortality rates based on the International Classification of Diseases, revisions 8, 9, and 10 [23].

This study was approved by Welfare and Health Administration of Finland (DNro 639/103/91)

\section{Results}

By the end of 2005, 528 (91.1\%) of the 579 patients with an MM prosthesis and 1299 (82.0\%) of the 1585 patients with an MP prosthesis had died. The mean follow-up times were 17.9 and 16.7 years, respectively (Table 1 ). Both groups of patients had a total mortality rate slightly below the national average. All-cause mortality was significantly reduced in both groups during the first postoperative decade, similar to that of the general population during the second postoperative decade, and was significantly increased thereafter (Table 2). The RR figures did not differ significantly between groups in any follow-up category (Table 2).

Cancer mortality in the MM group was similar to that in the general population, but the rate was significantly reduced in the MP group (Table 3, 4). During the first 20 years after THA, the SMR for the MM group (1.01) was higher than that for the MP group (0.74); RR 1.36 (95\% CI 
Table 1: Number of patients $(\mathrm{n})$ with metal-on-metal or metal-on-polyethylene prostheses stratified by age at operation and number of person-years at risk up to the end of $\mathbf{2 0 0 5}$ by age at follow-up.

\begin{tabular}{|c|c|c|c|c|}
\hline \multirow[t]{2}{*}{ Age (years) } & \multicolumn{2}{|c|}{ Metal-on-metal prosthesis } & \multicolumn{2}{|c|}{ Metal-on-polyethylene prosthesis } \\
\hline & $\mathbf{n}$ & Person-years & $\mathbf{n}$ & Person-years \\
\hline 20 to 29 & 2 & 15.5 & 4 & 7.1 \\
\hline 30 to 39 & 6 & 28.7 & 16 & 107.0 \\
\hline 40 to 49 & 25 & 176.2 & 55 & 354.7 \\
\hline 50 to 59 & 145 & 855.6 & 291 & 1800.0 \\
\hline 60 to 69 & 278 & 2836.3 & 779 & 6694.5 \\
\hline 70 to 79 & 113 & 3898.4 & 419 & 10848.2 \\
\hline$\geq 80$ & 10 & 2374.3 & 21 & 6595.5 \\
\hline Total & 579 & 10185.1 & 1585 & 26406.9 \\
\hline
\end{tabular}

1.02-1.79). After 20 years, however, there was no practical difference between groups (Table 4).

Cardiovascular diseases dominated as the cause of mortality in both groups; $57 \%$ of the MM group and $54 \%$ of the MP group died from cardiovascular disease. Allover cardiovascular mortality was low during the first decade postoperatively, equivalent during the next decade, and slightly increased after 20 years postoperatively (Table 5). After 20 years, the SMR was 1.60 (95\% CI 1.32-1.92) for women in the MP group compared to 1.45 (95\%CI 1.16-1.78) for women in the MM group. These figures were slightly lower for men; 1.09 for men in the MP group (95\% CI $0.80-1.44$ ) and 1.26 for men in the MM group (95\% CI 0.82-1.84). The increase in mortality after 20 postoperative years was observed for all forms of vascular disease, including cerebrovascular diseases for which the SMRs were 1.56 (95\% CI 1.07 - 2.18) in the MM group and 1.22 (95\% CI 0.84 -1.96) in the MP group.

Diabetic mortality was low in the MP group and slightly decreased in the MM group, but the number of patients was small (Table 3). There was a slightly increased risk for dementia or Alzheimer's disease in the MP group (1.20), which increased with an increase in the time after surgery. After 20 years postoperatively, there were 37 recorded cases with an SMR of 1.54 (95\% CI 1.08 - 2.12). In the MM group, the total risk for this disease was close to that of the normal population (0.96) (Table 3). After 20 years, 22 patients in the MM group died from this disease; the SMR was 1.29 (95\% CI 0.81 - 1.29).
Mortality from respiratory diseases was low in both groups (Table 3). The SMR for the MM group remained low during the first two decades (0.53) and increased slightly thereafter (0.76). On the other hand, the SMR for the MP group increased from 0.66 to 1.34 during the same time period.

Mortality from genitourinary diseases was slightly decreased in the MM group and slightly increased in the MP group (Table 3). After 20 years, the SMR for these diseases in the MM group was 0.77 and 2.13 in the MP group, but the number of patients was too small to demonstrate statistical significance.

Accidental deaths in both groups were slightly and equally reduced. In patients over 80 years of age, however, accidental death due to falling was significantly reduced in the MP group (SMR 0.45; observed 8, expected 17.72, $95 \%$ CI $0.19-0.88)$ compared to that in the MM group (0.87).

\section{Discussion and Conclusions}

Total hip arthroplasty dramatically improves a patient's quality of life, but exposes patients to chronic stress from cobalt and chromium ions and particles. The MM THA group included only patients implanted with the firstgeneration MM design. The material of the McKee-Farrar hip prosthesis was a cast cobalt-chromium-molybdenum alloy, with a carbon content of approximately $0.2 \%$ that underwent subsequent heat treatment. Its metallurgical, tribological, and structural properties are inferior to 
Table 2: Observed number of deaths (Obs) (all causes) and standardised mortality ratio (SMR) and rate ratio (RR) among patients with metal-on-metal and metal-on-polyethylene total hip prostheses for osteoarthritis by number of postoperative years.

\begin{tabular}{|c|c|c|c|c|c|c|c|c|}
\hline \multirow[t]{2}{*}{$\begin{array}{l}\text { Follow-up time, } \\
\text { completed years }\end{array}$} & \multicolumn{3}{|c|}{ Metal-on-metal prosthesis $(n=579)$} & \multicolumn{3}{|c|}{$\begin{array}{c}\text { Metal-on-polyethylene prosthesis }(\mathrm{n}= \\
1585)\end{array}$} & \multirow[b]{2}{*}{$\mathbf{R R}$} & \multirow[b]{2}{*}{$95 \% \mathrm{Cl}$} \\
\hline & Obs & SMR & $95 \% \mathrm{Cl}$ & Obs & SMR & $95 \% \mathrm{Cl}$ & & \\
\hline 0 to 1 & 16 & 0.59 & $0.34-0.96^{*}$ & 35 & 0.37 & $0.26-0.51^{* * *}$ & 1.61 & $0.83-2.98$ \\
\hline 2 through 9 & 122 & 0.77 & $0.64-0.91^{* *}$ & 342 & 0.70 & $0.63-0.78^{* * *}$ & 1.09 & $0.88-1.35$ \\
\hline 10 through 19 & 200 & 0.94 & $0.81-1.06$ & 611 & 0.96 & $0.89-1.04$ & 0.97 & $0.82-1.14$ \\
\hline $20+$ & 190 & 1.20 & $1.04-1.37 *$ & 311 & 1.38 & $1.23-1.53^{* * *}$ & 0.87 & $0.72-1.05$ \\
\hline Total & 528 & 0.95 & $0.87-1.02$ & 1299 & 0.90 & $0.85-0.95^{* * *}$ & 1.05 & $0.95-1.16$ \\
\hline
\end{tabular}

those of modern MM bearings with an average annual wear rate of the femoral heads ranging from 3.3 to $6.6 \mu \mathrm{m}$ and that of cups from 2.1 to $4.9 \mu \mathrm{m}$ [24]. Due to the high wear rate, we can assume that if excessive metal ion loading from the McKee-Farrar components did not increase the risk of mortality within this cohort, such risk would not be obvious in recipients of MM implants with improved wear characteristics.

All previous reports of the mortality of THA patients studied a period of up to only 10 years after surgery. According to the results of these studies, the 10-year life expectancy of THA patients is better than that of the general population $[25,26]$, which we also observed in the present study. Patient selection, i.e., the 'healthy patient effect', probably explains a major part of the better survival, but the reason for the duration of this effect in different disease groups is not known. In a Swedish Knee Arthroplasty Register study [27], patients with implantation of knee prostheses for OA had a reduced overall mortality during the first 12 postoperative years, which then increased and became significantly higher than that of the general population. Cardiovascular, gastrointestinal, and genitourinary diseases were the main causes for the increased mortality. The authors suspected a link between the early onset of knee OA and increased mortality. Another study reported reduced SMRs in THA patients aged 65 years and over in the United Kingdom, and an increased mortality rate in younger patients; the preoperative indications, however, were not reported [28].

Total mortality in the present study did not differ significantly between the MM and MP groups across the postoperative decades. After 20 years postoperatively, both groups showed significantly increased mortality due to cardiovascular disease. Altered cardiac function is reported among hard metal workers. A prolonged left ventricular relaxation time without clinical consequences was observed in a series of 203 Finnish cobalt production workers [29]. The authors concluded that cobalt accumulation in the myocardium could affect its function. An estimated daily intake of 6 to $8 \mathrm{mg}$ of cobalt chloride or cobalt sulfate induces cardiomyopathy in heavy beer drinkers when cobalt is used as a foam stabilising agent in the beer [30]. Cardiac function, specifically in terms of cobalt or chromium concentration in the myocardial cells, in THA patients after long-term use of MM or MP prostheses has not been studied. Frustaci et al. [31] observed a large increase in the levels of different trace elements in the myocardium of 13 patients with idiopathic dilated cardiomyopathy, with a 13-fold increase in the concentration of cobalt and a 4-fold increase in the concentration of chromium compared to controls. Relationship of the elevated cobalt and chromium concentrations in the serum of THA patients and cardiomyopathy requires further studies.

In a large cohort of Finnish OA patients with an MP hip prosthesis that was not included among patients in the present study with 153000 person-years and a mean follow-up of 6.2 years, the SMR for all-site cancer was reduced to 0.54 [32], and in the present series, after a mean of 16.2 years, it was still significantly reduced (0.76). According to a meta-analysis of six Nordic cohorts operated on for OA, covering 374000 person-years and a mean follow-up of 7.6 years, the standardized incidence 
Table 3: Observed number of deaths (Obs) and standardised mortality ratio (SMR) among patients with metal-on-metal and metal-on-polyethylene total hip prostheses for osteoarthritis in the main disease groups.

\begin{tabular}{|c|c|c|c|c|c|c|}
\hline \multirow[t]{2}{*}{ Cause of death } & \multicolumn{3}{|c|}{ Metal-on-metal prosthesis $(n=579)$} & \multicolumn{3}{|c|}{ Metal-on-polyethylene prosthesis $(\mathrm{n}=1585)$} \\
\hline & Obs & SMR & $95 \% \mathrm{Cl} \neq$ & Obs & SMR & $95 \% \mathrm{Cl}$ \\
\hline Cancer & 96 & 0.97 & $0.79-1.18$ & 206 & 0.76 & $0.66-0.86 * * *$ \\
\hline Cardiovascular & 300 & 0.96 & $0.86-1.07$ & 702 & 0.90 & $0.84-0.97^{* *}$ \\
\hline Respiratory & 33 & 0.67 & $0.46-0.93 *$ & 101 & 0.78 & $0.64-0.94 * *$ \\
\hline Pneumonia & 28 & 0.87 & $0.58-1.25$ & 79 & 0.96 & $0.76-1.20$ \\
\hline $\begin{array}{l}\text { Alzheimer, } \\
\text { dementia }\end{array}$ & 28 & 0.96 & $0.64-1.38$ & 105 & 1.20 & $0.98-1.43$ \\
\hline Genitourinary & 8 & 0.90 & $0.39-1.76$ & 27 & 1.32 & $0.87-1.91$ \\
\hline Digestive system & 18 & 1.08 & $0.64-1.71$ & 45 & 1.07 & $0.78-1.43$ \\
\hline Diabetes & 6 & 0.80 & $0.29-1.74$ & 7 & 0.42 & $0.17-0.86^{*}$ \\
\hline $\begin{array}{l}\text { Accidents and } \\
\text { violence }\end{array}$ & 14 & 0.78 & $0.42-1.30$ & 38 & 0.79 & $0.56-1.07$ \\
\hline All causes & 528 & 0.95 & $0.87-1.02$ & 1299 & 0.90 & $0.85-0.95 * * *$ \\
\hline
\end{tabular}

Table 4: Observed number of cancer deaths (Obs) and standardised mortality ratio (SMR) and rate ratio (RR) with $95 \%$ confidence intervals of patients with metal-on-metal and metal-on-polyethylene total hip prostheses stratified by number of postoperative years.

\begin{tabular}{|c|c|c|c|c|c|c|c|c|}
\hline \multirow{2}{*}{$\begin{array}{l}\text { Follow-up time, } \\
\text { completed years }\end{array}$} & \multicolumn{3}{|c|}{ Metal-on-metal prosthesis $(n=579)$} & \multicolumn{5}{|c|}{ Metal-on-polyethylene prosthesis $(n=1585)$} \\
\hline & Obs & SMR & $95 \% \mathrm{Cl} \neq$ & Obs & SMR & $95 \% \mathrm{Cl}$ & $\mathbf{R R}$ & $95 \% \mathrm{Cl}$ \\
\hline 0 to 1 & 2 & 0.35 & $0.04-1.27$ & 3 & 0.14 & $0.03-0.41^{* * *}$ & 2.51 & $0.21-21.94$ \\
\hline 2 through 9 & 29 & 0.92 & $0.62-1.32$ & 77 & 0.78 & $0.61-0.96^{*}$ & 1.19 & $0.74-1.85$ \\
\hline 10 through 19 & 43 & 1.19 & $0.86-1.59$ & 89 & 0.84 & $0.67-1.02$ & 1.42 & $0.96-2.07$ \\
\hline $20+$ & 19 & 0.84 & $0.50-1.30$ & 33 & 0.89 & $0.61-1.24$ & 0.95 & $0.51-1.71$ \\
\hline Total & 93 & 0.97 & $0.78-1.18$ & 202 & 0.76 & $0.66-0.87^{* * *}$ & 1.27 & $0.98-1.63$ \\
\hline
\end{tabular}


Table 5: Observed number of cardiovascular deaths (Obs) and standardised mortality ratio (SMR) and rate ratio (RR) with $\mathbf{9 5 \%}$ confidence intervals of patients with metal-on-metal and metal-on-polyethylene total hip prostheses stratified by number of postoperative years.

\begin{tabular}{|c|c|c|c|c|c|c|c|c|}
\hline \multirow{2}{*}{$\begin{array}{l}\text { Follow-up time, } \\
\text { completed years }\end{array}$} & \multicolumn{3}{|c|}{ Metal-on-metal prosthesis $(n=579)$} & \multicolumn{5}{|c|}{ Metal-on-polyethylene prosthesis $(n=1585)$} \\
\hline & Obs & SMR & $95 \% \mathrm{Cl}$ & Obs & SMR & $95 \% \mathrm{Cl}$ & $\mathbf{R R}$ & $95 \% \mathrm{Cl}$ \\
\hline $0-1$ & 7 & 0.46 & $0.04-1.27$ & 27 & 0.50 & $0.03-0.41^{* * *}$ & 0.91 & $0.98-1.163$ \\
\hline $2-9$ & 75 & 0.81 & $0.62-1.32$ & 193 & 0.70 & $0.61-0.96^{*}$ & 1.16 & $0.88-1.52$ \\
\hline $10-19$ & 103 & 0.85 & $0.86-1.59$ & 326 & 0.97 & $0.67-1.02$ & 0.87 & $0.69-1.10$ \\
\hline $20+$ & 115 & 1.40 & $0.50-1.30$ & 156 & 1.40 & $0.61-1.24$ & 1.00 & $0.78-1.28$ \\
\hline Total & 300 & 0.96 & $0.78-1.18$ & 702 & 0.90 & $0.66-0.87^{* * *}$ & 1.07 & $0.93-1.22$ \\
\hline
\end{tabular}

rate (SIR) was significantly reduced (SIR 0.93, 95\% CI 0.91-0.95) [33]. In another meta-analysis [34] of patients with 1.1 million person-years and a mean follow-up time of 6.2 years operated on for all indications, the SIR was close to unity, 0.98, 95\% CI 0.98-0.99). Goldachre et al. [35] also reported an SIR of 0.98, 95\% CI 0.94-1.01) among 25047 THA patients from the United Kingdom with a mean follow-up of 7.7 years. OA itself is also associated with a low comorbidity of cancer. Thomas et al. [36] reported a low SIR of 0.85 (95\% CI 0.81-0.88) for men and 0.83 (95\% CI 0.80-0.86) for women among patients with all forms of OA in a Scottish cohort. It seems that first-generation MM or MP prostheses do not expose patients to an increased risk of cancer. Cobalt and chromium are essential trace elements and hence a DNA repair system may exist in the body to rectify DNA damage caused by these ions. Nucleotide excision repair effectively removes chromium from DNA adducts [37]. In addition, macrophages detoxify the genotoxic and cytotoxic effects of $\mathrm{CoCr}$ particles in vitro [38].

Although cancer genesis may thus be controlled by these mechanisms, the long-term stress caused by cobalt and chromium ions may eventually exhaust these functions, which may lead to cellular senescence and apoptosis and eventually to a functional failure of the affected organs. Such development may be reflected by the mortality from other causes.

The number of patients that died from gastrointestinal and urogenital diseases in the present series was too small to determine the influence of the implantation on mortality 20 years postoperatively. The significant increase in mortality from dementia or Alzheimer disease 20 years after the MP group is noteworthy. Scientific evidence of a relationship between cobalt or chromium exposure and this disease, however, is lacking.

A limitation of this study is the relatively small number of patients and therefore chance may explain some of the results. Both groups showed similar development of all site mortality, however, over a long follow-up period. In addition, revisions or bilateral operations were not reported, but both groups were certainly exposed to cobalt and chromium debris due to the degradation of nano-sized metal particles. To our knowledge, revision was usually performed with the insertion of a new MM or MP prosthesis.

Over $90 \%$ of the patients MM group in the present series had died. Therefore, their causes of death will not change. Older cells are less tolerant than younger cells to cobalt-chromium particles. Nanometer-sized cobaltchromium particles induce a greater loss of viability in older human fibroblast in vitro than in cells from younger patients [39]. After the $20^{\text {th }}$ post-operative year, both the MM and MP hip prosthesis group had significantly increased mortality. Thus, even longer follow-up times are needed to estimate the risk of death in patients with modern MM bearings.

\section{Competing interests}

The authors declare that they have no competing interests.

\section{Authors' contributions}

TV: study design, preparation of the manuscript; HB initiation of the study, revision of the manuscript; PPu: statistical analysis, revision of the manuscript; PPa study design, revision of the manuscript; EP: data collection (Finnish Cancer 
Registry), revision of the manuscript. All authors read and approved the manuscript.

\section{Author Details}

${ }^{1}$ Research Institute of Military Medicine, Helsinki, Finland, ${ }^{2}$ Clinics for Orthopaedics and Traumatology, Central University Hospital, Helsinki, Finland ${ }^{3}$ Department of Public Health, University of Helsinki, Helsinki, Finland, ${ }^{4}$ Orton Orthopaedic Hospital, Helsinki, Finland and ${ }^{5}$ Finnish Cancer Registry, Helsinki, Finland, and School of Public Health, University of Tampere, Tampere, Finland

Received: 7 November 2009 Accepted: 23 April 2010

Published: 23 April 2010

\section{References}

1. Amstutz HC, Beaulé PE, Dorey FJ, Le Duff MJ, Campbell PA, Gruen TA Metal-on-metal hybrid surface arthroplasty: two to six-year follow-up study. J Bone Joint Surg [Am] 2004, 86:28-39.

2. Daniel J, Pynsent PB, MCMinn DJ: Metal-on-metal resurfacing of the hip in patients under the age of 55 years with osteoarthritis. J Bone Joint Surg [Br] 2004, 86:177-184.

3. Saito S, Ryu J, Watanabe M, Ishii T, Saigo K: Midterm results of Metasul metal-on-metal total hip arthroplasty. J Arthroplasty 2006, 21:1105-1110

4. Hing CB, Back DL, Bailey M, Young DA, Dalziel RE, Shimmin AJ: The results of primary Birmingham hip resurfacings at a mean of five years: an independent prospective review of the first 230 hips. J Bone Joint Surg [Br] 2007, 89:1431-1438.

5. Doorn PF, Campbell PA, Worrall J, Benya PD, McKellop HA, Amstutz HC: Metal wear particle characterization from metal on metal total hip replacements: transmission electron microscopy study of periprosthetic tissues and isolated particles. J Biomed Mater Res 1998, 42:103-111.

6. Firkins PJ, Tipper JL, Saadatzadeh MR, Ingham E, Stone MH, Farrar R, Fisher $\mathrm{J}$ : Quantitative analysis of wear and wear debris from metal-on-metal hip prostheses tested in a physiological hip joint simulator. Biomed Mater Eng 2001, 11:143-157.

7. Catelas I, Campbell PA, Bobyn JD, Medley JB, Huk OL: Wear particles from metal-on-metal total hip replacements: effects of implant design and implantation time. Proc Inst Mech Eng [H] 2006, 220:195-208.

8. Case CP, Langkamer VG, James C, Palmer MR, Kemp AJ, Heap PF, Solomon $\mathrm{L}$ : Widespread dissemination of metal debris from implants. J Bone Joint Surg [Br] 1994, 76:701-712.

9. Shea KG, Lundeen GA, Bloebaum RD, Bachus KN, Zou L: Lymphoreticular dissemination of metal particles after primary joint replacements. Clin Orthop 1997, 338:219-226.

10. Urban RM, Jacobs JJ, Tomlinson MJ, Gavrilovic J, Black J, Peoc'h M: Dissemination of wear particles to the liver, spleen, and abdominal lymph nodes of patients with hip or knee replacement. J Bone Joint Surg [Am] 2000, 82:457-476.

11. Campbell P, Urban RM, Catelas I, Skipor AK, Schmalzried TP: Autopsy analysis thirty years after metal-on-metal total hip replacement. A case report. J Bone Joint Surg [Am] 2003, 85:2218-2222.

12. Urban RM, Tomlinson MJ, Hall DJ, Jacobs JJ: Accumulation in liver and spleen of metal particles generated at nonbearing surfaces in hip arthroplasty. J Arthroplasty 2004, 19(Suppl 3):94-101.

13. Goldsmith AA, Dowson D, Isaac GH, Lancaster JG: A comparative joint simulator study of the wear of metal-on-metal and alternative material combinations in hip replacements. Proc Inst Mech Eng [H] 2000, 214:39-47.

14. Coleman RF, Herrington J, Scales JT: Concentration of wear products in hair, blood, and urine after total hip replacement. BrMed J 1973, 1:527-529.

15. Jacobs JJ, Skipor AK, Doorn PF, Campbell P, Schmalzried TP, Black J, Amstutz HC: Cobalt and chromium concentrations in patients with metal on metal total hip replacements. Clin Orthop 1996, 329(Suppl):S256-263.

16. Sauvé P, Mountney J, Khan T, De Beer J, Higgins B, Grover M: Metal ion levels after metal-on-metal Ring total hip replacement: a 30-year follow-up study. J Bone Joint Surg [Br] 2007, 89:586-590.
17. MacDonald SJ, McCalden RW, Chess DG, Bourne RB, Rorabeck CH, Cleland D, Leung F: Metal-on-metal versus polyethylene in hip arthroplasty: a randomized clinical trial. Clin Orthop 2003, 406:282-296.

18. Case CP, Langkamer VG, Howell RT, Webb J, Standen G, Palmer M, Kemp A, Learmonth ID: Preliminary observations on possible premalignant changes in bone marrow adjacent to worn total hip arthroplasty implants. Clin Orthop 1996, 329(Suppl):S269-279.

19. Doherty AT, Howell RT, Ellis LA, Bisbinas I, Learmonth ID, Newson R, Case CP: Increased chromosome translocations and aneuploidy in peripheral blood lymphocytes of patients having revision arthroplasty of the hip. J Bone Joint Surg [Br] 2001, 83:1075-1081.

20. Daley B, Doherty AT, Fairman B, Case CP: Wear debris from hip or knee replacements causes chromosomal damage in human cells in tissue culture. J Bone Joint Surg [Br] 2004, 86:598-606.

21. Ladon D, Doherty A, Newson R, Turner J, Bhamra M, Case CP: Changes in metal levels and chromosome aberrations in the peripheral blood of patients after metal-on-metal hip arthroplasty. J Arthroplasty 2004, 19(Suppl 3):78-83.

22. Visuri T, Pukkala E, Paavolainen P, Riska EB: Cancer risk after metal on metal and polyethylene on metal total hip arthroplasty. Clin Orthop 1996, 329:\$280-289.

23. Statistics Finland: Causes of Death. Health 1999, 3:18-21.

24. Campbell P, Shen FW, McKellop H: Review article. Biologic and tribologic considerations of alternative bearing surfaces. Clin Orthop 2004, 418:98-111.

25. Visuri T, Pulkkinen P, Turula KB, Paavolainen P, Koskenvuo M: Life expectancy after hip arthroplasty. Case-control study of 1018 cases of primary arthrosis. Acta Orthop Scand 1994, 65:9-11.

26. Lie SA, Engesaeter LB, Havelin LI, Furnes O, Vollset SE: Mortality after total hip replacement: 0-10-year follow up of 39,543 patients in the Norwegian Arthroplasty Register. Acta Orthop Scand 2000, 71:19-27.

27. Robertsson O, Stefánsdóttir A, Lidgren L, Ranstam J: Increased long-term mortality in patients less than 55 years old who have undergone knee replacement for osteoarthritis: results from the Swedish Knee Arthroplasty Register. J Bone Joint Surg [Br] 2007, 89:599-603.

28. Ramiah RD, Ashmore AM, Whitley E, Bannister GC: Ten-year life expectancy after primary total hip replacement. J Bone Joint Surg [Br] 2007, 89:1299-1302

29. Linna A, Oksa P, Groundstroem K, Halkosaari M, Palmroos P, Huikko S, Uitti $\mathrm{J}$ : Exposure to cobalt in the production of cobalt and cobalt compounds and its effect on the heart. Occup Environ Med 2004, 61:877-885.

30. Barceloux DG: Cobalt. J Toxico/ Clin Toxicol 1999, 37:201-16.

31. Frustaci A, Magnavita N, Chimenti C, Caldarulo M, Sabbioni E, Pietra R, Cellini C, Possati GF, Maseri A: Marked elevation of myocardial trace elements in idiopathic dilated cardiomyopathy compared with secondary cardiac dysfunction. J Am Coll Cardiol 1999, 33:1578-1583.

32. Paavolainen P, Pukkala E, Pulkkinen $P$, Visuri $T$ : Causes of death after total hip arthroplasty: a nationwide cohort study with 24,638 patients. J Arthroplasty 2002, 17:274-81.

33. Visuri T, Pukkala E, Pulkkinen P, Paavolainen P: Decreased cancer risk in patients who have been operated on with total hip and knee arthroplasty for primary osteoarthrosis: a meta-analysis of 6 Nordic cohorts with 73,000 patients. Acta Orthop Scand 2003, 74:351-360.

34. Onega T, Baron J, MacKenzie T: Cancer after total joint arthroplasty: a meta-analysis. Cancer Epidemiol Biomarkers Prev 2006, 15:1532-1537.

35. Goldacre MJ, Wotton CJ, Seagroatt V, Yeates D: Cancer following hip and knee arthroplasty: record linkage study. Br J Cancer 2005, 11:1298-1301.

36. Thomas E, Brewster DH, Black RJ, Macfarlane GJ: Risk of malignancy among patients with rheumatic conditions. Int J Cancer 2000, 88:497-502.

37. Reynolds M, Peterson E, Quievryn G, Zhitkovich A: Human nucleotide excision repair efficiently removes chromium-DNA phosphate adducts and protects cells against chromate toxicity. J Biol Chem 2004, 279:30419-30424.

38. Papageorgiou I, Shadrick V, Davis S, Hails L, Schins R, Newson R, Fisher J, Ingham E, Case CP: Macrophages detoxify the genotoxic and cytotoxic effects of surgical cobalt chrome alloy particles but not quartz particles on human cells in vitro. Mutat Res 2008, 643(1-2):11-19. 
39. Papageorgiou I, Yin Z, Ladon D, Singh S, Newson R, Davis S, Fisher J, Ingham E, Case CP: Genotoxic effects of particles of surgical cobalt chrome alloy on human cells of different age in vitro. Mutat Res 2007, 619:45-58.

Pre-publication history

The pre-publication history for this paper can be accessed here:

http://www.biomedcentral.com/1471-2474/11/78/prepub

doi: 10.1186/1471-2474-11-78

Cite this article as: Visuri et al, A retrospective comparative study of mortality and causes of death among patients with metal-on-metal and metal-onpolyethylene total hip prostheses in primary osteoarthritis after a long-term follow-up BMC Musculoskeletal Disorders 2010, 11:78

Submit your next manuscript to BioMed Central and take full advantage of:

- Convenient online submission

- Thorough peer review

- No space constraints or color figure charges

- Immediate publication on acceptance

- Inclusion in PubMed, CAS, Scopus and Google Scholar

- Research which is freely available for redistribution

Submit your manuscript at www.biomedcentral.com/submit
() BioMed Central 